Trauma Berufskrankh 2012 - 14[Suppl 3]:251 DOI 10.1007/s10039-011-1836-7

Online publiziert: 22 . März 2012

(c) Springer-Verlag 2012

\title{
Th. Köhler
}

Deutsche Gesetzliche Unfallversicherung (DGUV), Landesverband Südwest, Heidelberg

\section{Begrüßung}

bestimmt profitieren wird, ist der Präsident der Deutschen Gesellschaft für Unfallchirurgie, Herr Prof. Pohlemann aus Homburg/Saar. Er ist heute bei uns und wird auch den Vorsitz im ersten Hauptthema übernehmen.

Seit 30 Jahren nehme ich regelmäßig an der Unfallmedizinischen Tagung in Baden-Baden teil. Viele von Ihnen sind genauso lange oder noch länger dabei. Und doch ist es dieses Mal deutlich anders. Denn der Bénazet-Saal, die $g u$ te Stube Baden-Badens, erstrahlt in neuem Glanz. Nach 7-monatiger Bauzeit und Kosten von über 8 Mio. EUR ist er komplett neu gestaltet. Die feierliche Wiedereröffnung fand erst vor wenigen Wochen statt. Mit Blick auf den seit langem feststehenden Termin für unsere Unfallmedizinische Tagung waren wir doch sehr erleichtert, dass die zeitlichen Vorgaben eingehalten wurden.

Ich grüße besonders die Richterinnen und Richter der Sozialgerichtsbarkeit, an der Spitze die Präsidentin des Landessozialgerichts Baden-Württemberg, Frau Haseloff-Grupp.

Ein herzliches Willkommen gilt den Vorstandsmitgliedern des Krankenhausträgervereins Heidelberg, v. a. den Vorsitzenden, Herrn Hippler und Herrn Dr. Flothmann. Der Verein ist der Träger der BG-Kliniken (BG: Berufsgenossenschaft) in Tübingen und Ludwigshafen.

Ein ganz besonderer Gruß gilt natürlich auch den Mitgliedern des Beirats unseres Landesverbands, an der Spitze der Vorsitzende Herr Fellmer. Der Beirat begleitet unsere Arbeit immer mit Engagement und großem Interesse an der Sache!

Das gilt auch für Herrn Dr. Kranig, der bei der DGUV die Abteilung Versicherung und Leistungen leitet. Natürlich freue ich mich, dass auch meine Kollegen Herr Klementz vom Landesverband Südost und Herr Dr. Platz vom Landesverband Mitte hier sind - ein schönes Zeichen der guten Zusammenarbeit unserer Landesverbände.

Bei einer so illustren Gästeschar läuft man immer Gefahr, dass eine namentliche Begrüßung nicht vollständig ist; deswegen schlicht und einfach ein herzliches Willkommen an Sie alle!

Bei einer komplexen Kongressmaterie ist jeder Veranstalter froh, wenn er die wissenschaftliche Leitung in routinierten Händen weiß. Wir haben das große Glück, auch dieses Mal wieder auf ein kompetentes Duo setzen zu dürfen. Für beide ist es eine Premiere; der Generationenwechsel an der ärztlichen Spitze der BG-Kliniken in Ludwigshafen und Tübingen ist vollzogen. Von den Herren Professoren Wentzensen und Weise, die uns viele Jahre großartig durch das Programm führten, ging die Leitung auf Herrn Prof. Grützner und Herrn Prof. Stöckle über. Ich bin ganz sicher, dass auch Sie beide diese Aufgabe mit Bravour meistern werden.

Frei nach Goethe sage ich jetzt: „Der Worte sind genug gewechselt, lasst uns auch endlich Taten sehen"

und übergebe das Wort an Herrn Prof. Grützner und Herrn Prof. Stöckle.

\section{Korrespondenzadresse}

\section{Th. Köhler}

Deutsche Gesetzliche Unfallversicherung (DGUV), Landesverband Südwest, 69004 Heidelberg thomas.koehler@bgrci.de 